\title{
Water resources assessment and prediction in China
}

\author{
Wang Guangsheng, Dai Ning, Yang Jianqing, and Wang Jinxing \\ Bureau of Hydrology of MWR, Baiguang Road, Beijing, 100053, China \\ Correspondence to: Wang Guangsheng (gshwang@mwr.gov.cn) \\ Published: 17 October 2016
}

\begin{abstract}
Water resources assessment in China, can be classified into three groups: (i) comprehensive water resources assessment, (ii) annual water resources assessment, and (iii) industrial project water resources assessment. Comprehensive water resources assessment is the conventional assessment where the frequency distribution of water resources in basins or provincial regions are analyzed. For the annual water resources assessment, water resources of the last year in basins or provincial regions are usually assessed. For the industrial project water resources assessment, the water resources situation before the construction of industrial project has to be assessed. To address the climate and environmental changes, hydrological and statistical models are widely applied for studies on assessing water resources changes. For the water resources prediction in China usually the monthly runoff prediction is used. In most low flow seasons, the flow recession curve is commonly used as prediction method. In the humid regions, the rainfall-runoff ensemble prediction (ESP) has been widely applied for the monthly runoff prediction. The conditional probability method for the monthly runoff prediction was also applied to assess next month runoff probability under a fixed initial condition.
\end{abstract}

\section{Introduction}

Water is the most vital natural resource on the earth that cannot be substituted. It is necessary for human lives and for maintaining the environment on which all creatures rely. Although water is a renewable resource, which can be replenished, the total volume of available water in a definitive area for a definitive period is limited. The volume of water resources in China, either per capita or per hectare farmland, is less than the world average, and it is unevenly distributed in time and space. In pace with the social and economic progress and population growth, the human water demand increases every year. As a result, water shortage has occurred in many regions, conflicts between water supply and demand are becoming increasingly serious. Water resources assessment and prediction tries to assess normal and probability distributions of available water resources, and to predict the volume of available water in future. It does not only concern industry, agriculture and the aquatic environment, but it also deals with people's daily life. Therefore,water resources assessment and prediction are highly important to society.

\section{General situation of water resources assessment}

Based upon the basin' area, there are 10 first class water resources regions in China, namely, the Yangtze River, Yellow River, Huaihe River, Haihe River, Liaohe River, Songhua River, Northwest Rivers, Southwest Rivers, Pearl River and Southeast Rivers. These water resources regions are the basic unit of water resources management. The first water resources assessment in China was carried out in the 1980s for the above-mentioned water resources regions, and these comply with the provincial administrative regions to meet the need of administrative management.

Water resources in China are monitored through hydrological stations; the monitoring elements include, e.g., precipitation, surface water level, groundwater level, discharge. Most of the time series of hydrological observations started in the 1950s.

The water resources assessment index includes precipitation, water quantity and quality. In detail:

- Precipitation: recorded by standard rain-gauges

- Surface water: formed by local precipitation, inflow and outflow of the region 
- Groundwater: formed by local precipitation

- Total volume of water resources: surface water plus groundwater

- Water storage: reservoirs, shallow groundwater storage in the plains

- Development and utilization of water resources: water supply, water use, water consumption, wastewater discharge

\section{- Water quality}

The water resources assessment aims to evaluate the volume of natural available water. It often means to assess the runoff generated from precipitation. Nowadays, observed runoff series are often disturbed by water diverting, water withdrawal and reservoir operation. Therefore, the difference between observed and the natural water flow is rather significant. Therefore, to assess the volume of natural water resources, the data series need to be naturalized. For the naturalization, water withdrawal by industry and agricultural irrigation, diverted water of cross-basins and dam regulation have to be considered by water balance modeling. Currently, water use of many small irrigation projects has not been monitored yet. Especially, volume of groundwater irrigation, is generally estimated by using water quota according to the irrigation area and kinds of crops, thus the required accuracy often cannot be satisfied.

Water resources assessment in China can be classified into three groups: (i) comprehensive water resources assessment, (ii) annual water resources assessment, and (iii) industrial project water resources assessment.

Ad (i): for the comprehensive water resources assessment, the annual normal distribution and probability distribution of water resources are analyzed and assessed at the scales of basins and provincial regions. Generally, the Pearson type III distribution function is used for the probability analysis. Two comprehensive water resources assessment have been carried out in China. The first assessment was carried out in 1980 with the data series from 1956-1979; and the second assessment was in 2003 with the data series from 1956-2000.

Ad (ii): for the annual water resources assessment, the water resources of the last year are assessed in basins and provincial regions. Their results areusually published in the China Water Resources Bulletin, the Gazette of River Sediment in China, and the Groundwater Bulletin.

Ad (iii): for the industrial project water resources assessment, the water resources situation before the constructing of industry projects has to be assessed, including rationality of water abstraction and water use, available water resources (quantity and quality), reliability of water supply, and effect of wastewater discharge into water environment.

In recent years, the increasing human activity and climate change, change the status of water resources. They also cause non-consistent water resources data series (the past situation deviates from the future situation, i.e. non-stationarity). The basic principle of water resources assessment is to use the historic data series to assess future water resources, the historic data series is expected to represent the water resources situation in the future. Thus, problems have emerged, as the environment and climate have changed. To solve this problem, studies are undertaken. One effective solution is hydrological modeling (Zhang and Wang, 2007), where the change of water resources as response to precipitation and temperature change was studied. The hydrological model Xinanjiang (Zhao, 1992), SWAT and VIC are applied in the studies. Another approach is statistics modeling, which combines the changing trend in runoff series with a probability model (Xie et al., 2009). It is suitable for basins whose landscape has been changed by human activity. The trend in runoff change is brought into regular pattern year by year in the model. The water resources situation is predicted under the assumption that the human activity continues.

\section{Water resources prediction}

In operational water resources management, long-term runoff predictions are frequently made since it is important in supporting dam operation, river flow dispatch, cross-basin water diversion, especially during a drought. As water resources become more important and water resources management is enforced, long-term runoff predictions are playing a more important role. For this kind of prediction, the probability model was widely used, and methods based on flow recession model have been developed for low flow conditions, while the ensemble prediction (ESP) also has been put into use in recent years. Usually, these predictions have the mean monthly discharge as the predicting target. Similar as with water resources assessment, time series that are used to calibrate the water resource prediction model need to be naturalized. Water withdrawal by industry and agriculture irrigation, cross-basin water transfer and dam regulation have to be considered through water balance modeling.

\subsection{Low flow period prediction model}

Low flow period usually are characterized by lack of rainfall, and hence runoff mainly is the base flow from water storage in a basin. In the northeast and northwest mountainous areas, runoff in spring also comes from snow melting. Because of the shortage of runoff in low flow period, the prediction becomes vital to irrigation and water supply management. Base on the recession model $Q_{t}=Q_{0} e^{-\beta t}$, many correlation diagrams and simple equations can be further developed. One of the most simple and preferred method by engineering hydrologist is described below. 


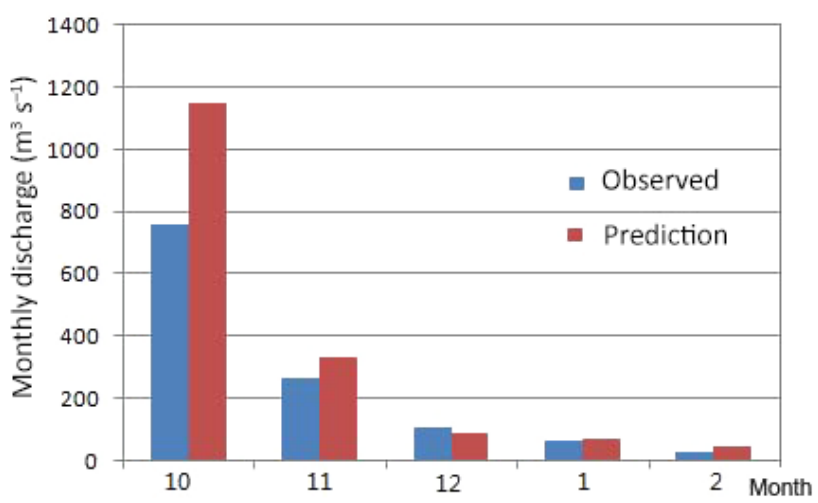

Figure 1. Predicted and observed discharge from October 2003 to February 2004 at the Jiangqiao station in the Nenjiang river.

The mean monthly discharge can be derived from the following recession model:

$\overline{Q_{\mathrm{m}}}=\frac{1}{n d} \sum_{i=1}^{n d} Q_{t 0}\left(e^{-\beta}\right)^{i}=Q_{t 0}\left[\frac{1}{n d} \sum_{i=1}^{n d}\left(e^{-\beta}\right)^{i}\right]$

where, $\overline{Q_{\mathrm{m}}}$ is mean monthly discharge, $Q_{t 0}$ is initial time discharge; $n d$ is number of days in a month. The above equation can be rewritten as follows:

$\overline{Q_{m 1}}=K_{m 1} Q_{t 0}$

where, $K_{m 1}=\left[\frac{1}{n d} \sum_{i=1}^{n d}\left(e^{-\beta}\right)^{i}\right]$

Equation (2) is used to predict next month runoff. The monthly runoff for the low flow period also can be predicted one step forward:

$\overline{Q_{m i}}=K_{m i} Q_{t 0}$

where, $m i$ is month $i$.

In practice, the mean monthly discharge at the end of rainy season or even within the whole low flow period can be predicted with reliable results. Since the base flow from groundwater varies for different $Q_{t 0}$, the coefficient of percolation that is represented by $\beta$ in Eq. (1) very likely is different. Therefore, it is recommended to look for a representative value or relatively stable value of $Q_{t 0 h}$ for the same time period and its corresponding mean monthly discharge $\overline{Q_{m i}}$ from historical data series, to allow to fix the $K_{m i}$ as follows:

$K_{m i}=\frac{\overline{Q_{m i h}}}{Q_{t 0 h}}$

Figure 1 gives the predicted monthly discharge at the Jiangqiao station in the Nenjiang river in the Songhua river basin in northeast China from October 2003 to February 2004. The basin area is $162600 \mathrm{~km}^{2}$, and the daily discharge of 30 September 2003 was take as the initial discharge $Q_{t 0}$.

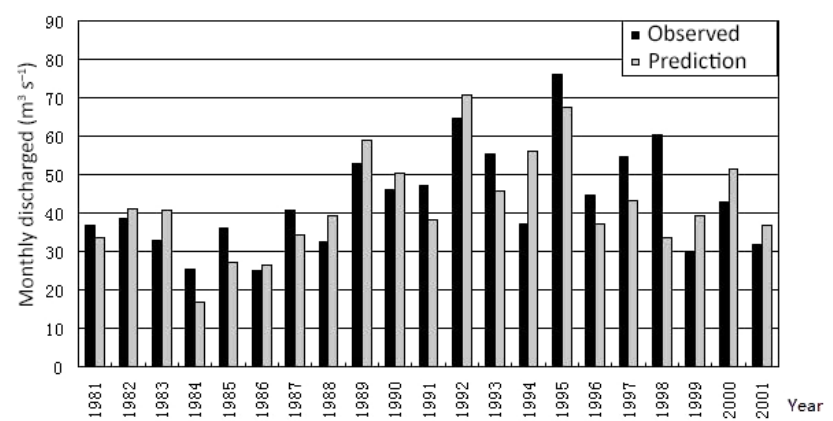

Figure 2. Predicted and observed monthly discharge in March at the Jiangqiao station.

In the snow season, snow melting hydrological models and multiple regression equations are used to predict the monthly runoff. Due to its simplicity, in principle, and ease of use, multiple regression is more preferred by engineering hydrologists, where the monthly snowfall, temperature, initial base flow are the main variables in the equation. For example, the monthly discharge in March (Mar) at the Jiangqiao station can be predicted using the following regression equation:

$\overline{Q_{m 3}}=1.1894 \overline{Q_{m 2}}+0.45894 P_{10 m-2 m}+3.28631 \overline{T_{m 3}}$

where, $\overline{Q_{m 3}}$ is the mean monthly discharge in March (Mar); $\overline{Q_{m 2}}$ is the mean monthly discharge in February (Feb); $P_{10 m-3 m}$ is the basin average snowfall from October to February; $\overline{T_{m 3}}$ is the mean temperature in March (Mar). The predicted monthly discharge in March for the years 19812001 is shown in Fig. 2.

\subsection{The rainfall runoff ensemble prediction}

Since last decade,the rainfall runoff ensemble prediction (ESP) has been studied and monthly runoff prediction has been carried out in humid regions. Usually, in humid regions, hydrological models can produce reliable forecasts and the initial soil moisture condition has a determinative effect on runoff generation. In arid regions, soil moisture generally is stable, remaining at a very low level, and runoff generation is less affected by initial soil moisture. Generally speaking, future runoff is mainly determined by future rainfall, where, future precipitation is rather a random term, while the initial soil moisture can be modeled reliably and affect future runoff in humid regions. Thus, the rainfall runoff ESP is more valuable in humid regions than in arid regions.

The Xinanjiang model is often used in rainfall runoff ESP in China. It is usually operated with a time interval of 1 day. Most hydrological models are used for flood forecasting, while long-term ESP should meet the need of water resources management since low flow forecast accuracy is especially important for water resources management. However, in this case, it is likely that model parameters need to be refitted for low flow forecasting. In general, precipitation series used for 
Table 1. Observed and predicted monthly discharge from July to October 2007 at the Danjiangkou reservoir.

\begin{tabular}{lrrrrrrr}
\hline Month & Observed $\left(\mathrm{m}^{3} \mathrm{~s}^{-1}\right)$ & \multicolumn{6}{c}{ Prediction $\left(\mathrm{m}^{3} \mathrm{~s}^{-1}\right)$} \\
\cline { 3 - 8 } & & Expectation & $10 \%$ & $25 \%$ & $50 \%$ & $75 \%$ & $90 \%$ \\
\hline 7 & 4408.2 & 2056.5 & 3169.1 & 2613.1 & 1994.8 & 1376.9 & 821.0 \\
8 & 2567.2 & 1992.6 & 3394.9 & 2703.1 & 1932.9 & 1164.1 & 471.2 \\
9 & 1381.6 & 1969.5 & 3761.2 & 2893.9 & 1930.2 & 966.8 & 99.2 \\
10 & 565.6 & 672.4 & 2265.9 & 1344.8 & 659.0 & 265.8 & 96.0 \\
\hline
\end{tabular}

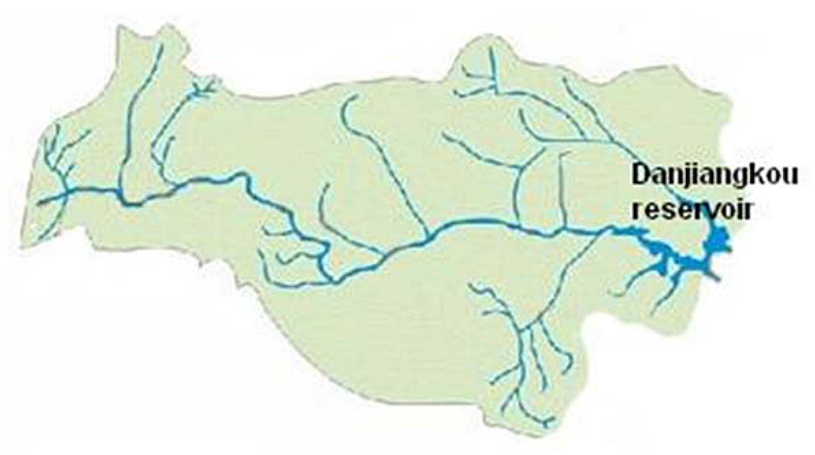

Figure 3. Basin area and river network of the Danjiangkou reservoir.

ESP requires time series exceeding 30 years. Practically, 1week forecasted precipitation can be considered to be valuable for water resources management and flood mitigation. To improve the prediction, precipitation of the first week in each historical monthly precipitation series used in ESP should be replaced by the forecasted precipitation. Thus, the mathematical expectation value and probability distribution of the monthly discharge can be reliably predicted. The Pearson III, normal and log-normal probability distributions can be used for discharge probability analysis.

In China, application of the long-term rainfall runoff ESP is still in a development phase. A number of research studies have been carried out, but have been limited to part of southern China rivers. The most significant case study is for the Danjiangkou reservoir.

The Danjiangkou reservoir is located upstream of the Han river in the Yangtze river basin in south China. The basin area is about $95200 \mathrm{~km}^{2}$, annual precipitation varies between $800-1100 \mathrm{~mm}$, and the mean annual discharge is $1200 \mathrm{~m}^{3} \mathrm{~s}^{-1}$. The reservoir is located in a humid, and mountainous area. The basin area, river network and location of the reservoir are shown in Fig. 3. The Danjiangkou reservoir is an important water resource in the area. The special significance of the reservoir is that it is the source of water for the south-to-north water transfer project, which diverts water from south to north China.

The Xinanjiang model has been used in rainfall runoff modeling of the Danjiangkou reservoir, where, 30 years his- torical precipitation data series are available, and the Pearson III probability distribution function was used for the determination of the runoff probability. Since the reservoir is in a large humid basin and initial conditions substantially affect next month runoff, precipitation predictions of the first week are also used in each historical monthly precipitation series. The predicted (i.e. probabilities) and observed mean monthly discharge from July to October 2007 are shown in Table 1.

In operational ESP, the correlation of initial soil moisture and river base flow with next monthly river discharge are analyzed, and the higher correlation the more valuable the ESP. The ESP takes the same initial soil moisture, base flow, and input historical precipitation series to the hydrological model. Obviously, the coefficient of variation (CV) of the probability distribution of predicted monthly discharge should be less than the coefficient of variation $(\mathrm{CV})$ of the probability distribution of the historical monthly discharge. Otherwise, the rainfall runoff model would not adequately simulate the real situation or the initial condition does not affect the next month runoff.

In probability computing, a few historical severe storms, whose return period significantly exceed the length of ESP historical precipitation series, ought to be specially treated. A better way is to analyze their return period with longer hydrological records, instead within the ESP historical precipitation series. Otherwise, the same frequency would be likely to predict a higher result.

\subsection{Conditional probability}

For large river basin,whose area is at the scale of hundred thousand square kilometers, their upstream area usually is brumal mountainous, and the density of rainfall gauge network cannot satisfy the need of rainfall runoff models. Then, conditional probability models are commonly used for such kind of predictions as the model does not require precipitation input. The conditional probability method (Wang et al., 2008) has been used for the monthly discharge prediction since late 1990s, originally for spring season prediction for irrigation in the Songhua river basin in northeast China. Conditional probability means assessment of the probability distribution of future runoff under a fixed initial condition.It is recommended to use initial conditions to reduce the coefficient of variation $(\mathrm{CV}$, mean quadratic error) of the proba- 
Table 2. Correlation coefficient of the discharge of the end day of the current month and monthly discharge of the next month for major sections in large river basins.

\begin{tabular}{|c|c|c|c|c|c|c|c|c|c|c|c|}
\hline \multirow[b]{2}{*}{ Month } & \multicolumn{2}{|c|}{ Songhua river } & \multirow{2}{*}{$\begin{array}{r}\text { basin } \\
\text { Jianmusi }\end{array}$} & \multicolumn{2}{|c|}{ Yellow river } & \multirow{2}{*}{$\begin{array}{r}\text { basin } \\
\text { Huaxian }\end{array}$} & \multirow{2}{*}{$\begin{array}{c}\text { Huaihe river basin } \\
\text { Lutaizi }\end{array}$} & \multicolumn{2}{|c|}{ Yangtze river } & \multirow{2}{*}{$\begin{array}{r}\text { basin } \\
\text { Waizhou }\end{array}$} & \multirow{2}{*}{$\begin{array}{c}\text { Pearl river basin } \\
\text { Wuzhou }\end{array}$} \\
\hline & Jiangqiao & Haerbin & & Tongguan & Hishiguan & & & Cuntan & Xiangtan & & \\
\hline 1 & 0.97 & 0.75 & 0.93 & 0.54 & 0.96 & 0.94 & 0.64 & 0.87 & 0.84 & 0.83 & 0.83 \\
\hline 2 & 0.95 & 0.92 & 0.96 & 0.72 & 0.93 & 0.90 & 0.63 & 0.84 & 0.58 & 0.59 & 0.62 \\
\hline 3 & 0.78 & 0.84 & 0.95 & 0.67 & 0.88 & 0.85 & 0.57 & 0.70 & 0.63 & 0.73 & 0.90 \\
\hline 4 & 0.70 & 0.68 & 0.67 & 0.11 & 0.54 & 0.56 & 0.54 & 0.56 & 0.21 & 0.46 & 0.50 \\
\hline 5 & 0.69 & 0.79 & 0.90 & 0.82 & 0.43 & 0.42 & 0.80 & 0.24 & 0.45 & 0.48 & 0.48 \\
\hline 6 & 0.84 & 0.85 & 0.71 & 0.89 & 0.50 & 0.25 & 0.55 & 0.31 & 0.32 & 0.40 & 0.56 \\
\hline 7 & 0.78 & 0.83 & 0.74 & 0.63 & 0.16 & 0.35 & 0.57 & 0.43 & 0.59 & 0.68 & 0.58 \\
\hline 8 & 0.82 & 0.85 & 0.80 & 0.68 & 0.47 & 0.19 & 0.67 & 0.38 & 0.59 & 0.30 & 0.32 \\
\hline 9 & 0.76 & 0.90 & 0.93 & 0.86 & 0.63 & 0.30 & 0.79 & 0.49 & 0.78 & 0.86 & 0.78 \\
\hline 10 & 0.85 & 0.90 & 0.93 & 0.90 & 0.61 & 0.89 & 0.74 & 0.55 & 0.60 & 0.62 & 0.47 \\
\hline 11 & 0.97 & 0.96 & 0.95 & 0.95 & 0.88 & 0.81 & 0.62 & 0.78 & 0.56 & 0.62 & 0.83 \\
\hline 12 & 0.96 & 0.90 & 0.70 & 0.79 & 0.98 & 0.92 & 0.91 & 0.79 & 0.74 & 0.82 & 0.82 \\
\hline
\end{tabular}

bility distribution of the prediction monthly runoff, and thus reliability of the prediction can be improved.

Discharge of the end day of the current month is taken as the initial condition to predict next monthly discharge. The value of the conditional probability method is determined by the correlation between the initial condition and next month runoff. Generally, large basins have longer memories, with good correlations between initial condition and future runoff. The correlation coefficient of the discharge of the end day of the current month and the monthly discharge of the next month at selected river sections in major basins are shown in Table 2. The drainage areas of those sections are over ten thousands or hundred thousand square kilometers. The table shows that correlation of most sections in the low flow season are obviously strong, and even better than that in summer rainy season in the Songhua river and part of the Yellow river (northern region).

Two dimensional Log normal probability distribution functions are used for the conditional probability study. This function has been used for hydrological probability analysis already for a long time. It is a two dimensional analytic function:

$$
\begin{aligned}
& f(x, y)=\frac{1}{2 \pi \sigma_{x} \sigma_{y} \sqrt{1-\rho^{2}}} \\
& e^{-\frac{1}{2\left(1-\rho^{2}\right)}\left[\frac{\left(\ln x-a_{x}\right)^{2}}{2 \sigma_{x}^{2}}-2 \rho \frac{\left(\ln x-a_{x}\right)\left(\ln y-a_{y}\right)}{\sigma_{x} \sigma_{y}}+\frac{\left(\ln y-a_{y}\right)^{2}}{2 \sigma_{y}^{2}}\right]}
\end{aligned}
$$

where, $\rho$ is correlation coefficient between $\ln (x)$ and $\ln (y)$; $a_{x}$ is mean $\ln (x) ; \sigma_{x}$ is mean quadratic error of $\ln (x) ; a_{y}$ is mean $\ln (y) ; \sigma_{y}$ is mean quadratic error of $\ln (y)$.
Table 3. Observed and predicted monthly discharge $\left(\mathrm{m}^{3} \mathrm{~s}^{-1}\right)$ of July 1999 at the Haerbin station.

\begin{tabular}{lcccccc}
\hline observed & Expectation & $10 \%$ & $25 \%$ & $50 \%$ & $75 \%$ & $90 \%$ \\
\hline 1160 & 1680 & 2460 & 2000 & 1680 & 1370 & 1170 \\
\hline
\end{tabular}

Base on Eq. (6), the conditional Log normal probability distribution function $f(y)$ at $x=x^{*}$ can be derived:

$$
\begin{gathered}
f\left(y \mid x=x^{*}\right)=\frac{1}{\sigma_{y} \sqrt{2 \pi\left(1-\rho^{2}\right)}} \\
e^{-\frac{1}{2 \sigma_{y}^{2}\left(1-\rho^{2}\right)}\left[\ln y-a_{y}-\rho \frac{\sigma_{y}}{\sigma_{x}}\left(\ln x^{*}-a_{x}\right)\right]^{2}}
\end{gathered}
$$

Equation (7) is still a Log normal distribution function. The mathematical expectation value of $\ln (y)$ is $a_{y}+$ $\rho \frac{\sigma_{y}}{\sigma_{x}}\left(\ln x^{*}-a_{x}\right)$. The mean quadratic error of $\ln (y)$ is $\sigma_{y} \sqrt{\left(1-\rho^{2}\right)}$ where, if $\rho>0$, correlation exists between $x$ and $y$, and the mean quadratic error $<\sigma_{y}$; and if $\rho=0$, then the mean quadratic error $=\sigma_{y}$. The higher the correlation between $x$ and $y$, the smaller the mean quadratic error of probability distribution of $y$ is. The Log normal distribution of $x$ and $y$ should be formulated, then $a_{x}, \sigma_{x}, a_{y}, \sigma_{y}$ can be obtained, the correlation coefficient $\rho$ can be computed, and parameters of conditional distribution of $y$ can be fixed.

Figure 4 gives the cumulative Log normal distribution of the discharge on 30 June, at the Haerbin station in Songhua river in northeast China, whose basin area is $557200 \mathrm{~km}^{2}$. Figure 5 provides the comparison of conditional and non-conditional cumulative log normal distributions of the monthly discharge of July, at the Haerbin station, where, the mean quadratic error of conditional distribution is less than that of the non-conditional distribution. Observed and predicted monthly discharge of July 1999, at the Haerbin station are shown in Table 3. 


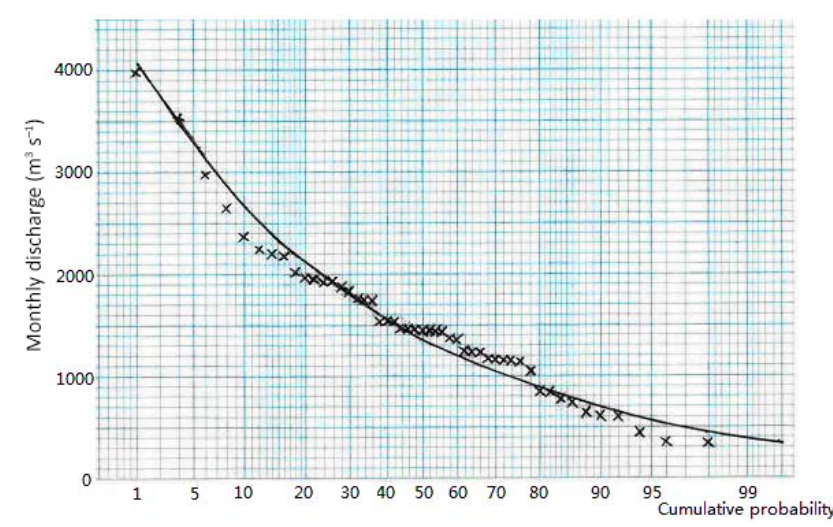

Figure 4. Predicted distribution of the discharge on 30 June at the Haerbin station using a conditional Log normal probability distribution.

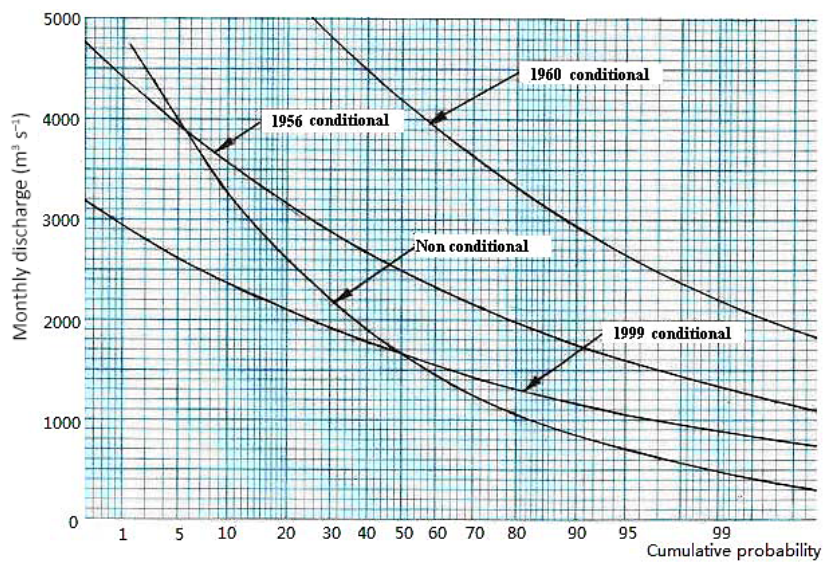

Figure 5. Conditional probability distribution of the monthly discharge of July for several years and the non-conditional distribution at the Haerbin station.

Conditional probability models to predict monthly runoff is applied mainly to large rivers. From the late 1990s, the model is used for water resources prediction in the Songhua and Laohe river basins in northeast China. In the 2005 and 2006 low flow seasons, severe low water occurred in the Pearl river, and sea water intruded the downstream river. To safeguard fresh water supply and to protect the aquatic environment, dam operation was optimized to release water to counteract the salty water tide. A conditional probability model was used to predict inflow of the Upper Pearl river at the Wuzhou station, which provided firm support to the decision-making.

\section{Conclusions}

Water resources assessment and prediction have provided strong support to water resources management and drought relief. As a follow-up of the implementation of a strict water resources management policy in China, water resources assessment and prediction will receive more attention in future.

Human activity, incl. climate change substantially changed the water resources status, and meanwhile bring non consistency in the past data series (non-stationarity) that are used for assessment of water resources and calibration of prediction models. This means that the historical data cannot represent future situation adequately. To make reliable water resources assessment and prediction, these changes impose serious challenges to the models. When climate changes, extreme weather events increase, such as severe floods and drought, inter annual variability of runoff increases, and within one year variability of runoff increases. Moreover, climate change in mountainous regions in north China causes decrease of snow melt runoff significantly, and water resources in the region become scarce in spring. All these issues need to be paid attention to and further studied for water resources assessment and prediction.

\section{Data availability}

Research data mainly refer information of river flow, can be accessed on web site of Ministry of Water Resources (http: //xxfb.hydroinfo.gov.cn/ssIndex.html.

Acknowledgements. The authors wish to thank Henny A. J. van Lanen from the Wageningen University for his comments, revision, and English smooth to improve the paper.

\section{References}

Wang, G., Ning, F., Xiao, F., and Jiang, T.: Applied Hydrological Forecasting Method, China Water and Power Press Beijing China, 2008 (in Chinese).

Xie, P., Chen, G., Lei, H., Han, S., Xia, J., and Zhu, Y.: Water resources assessment method under changing environment, Science Press, 2009 (in Chinese).

Zhang, J. and Wang, G.: Impact of climate change on hydrology and water resources, Science Press, 2007 (in Chinese).

Zhao, R.: The Xinanjiang model applied in China, J. Hydrol., 135, 371-381, 1992. 